\title{
The Enlightenment of Chinese Innovation Education-STEM
}

\author{
Zi-Liang An* \\ School of Electromechanical Engineering and Information \\ Shanghai Urban Construction Vocational College \\ Shanghai, China \\ Wen Wan \\ School of Electromechanical Engineering and Information \\ Shanghai Urban Construction Vocational College \\ Shanghai, China
}

\author{
Ning Wang \\ School of Mechanical Engineering \\ Shanghai Institute of Technology \\ Shanghai, China \\ Qiang Fu \\ Shanghai Jincheng College \\ Shanghai Jincheng College \\ Shanghai, China
}

\begin{abstract}
With the hot topic in the field of "Reform and Innovation of Education under the New Situation of the Belt and Road", the public awareness of STEM education has increased remarkably. STEM is the organic unification of science, technology, engineering and mathematics, and the purpose is to train high-level innovative talents. A comparison with the development of STEM in the U.S shows that we should incorporate Chinese characteristics into STEM and increase the cultivation of innovative talents in China. The study focuses on the shortage of STEM education in China at the current stage. To solve these problems, there are five solutions needed.
\end{abstract}

Keywords-STEM; Innovation Education; Chinese Characteristic

\section{INTRODUCTION}

With the implementation of "The Belt and Road" Initiative (BRI), which provides a new opportunity for the development of various types of education in China, especially for a new hot spot of STEM. STEM education concentrates on identification with and interest in learning, and it encourages collaboration when students work in groups. A Framework for Integrated STEM Education is the first resource to offer an integrated STEM curricula encompassing the entire K-12 spectrum [1], with complete grade-level learning of science, technology, engineering, and mathematics. As for STEM education in China, it has obtained a great an achievement in the market, policies and institutions. The main purpose of this paper is to discuss the role of Chinese culture in STEM education, to increase students' skill and knowledge, let them know how to use their knowledge creatively to get ahead in the drastic competitive global market.

\section{COMPARISON OF THE UNITED STATES AND CHINA}

\section{A. In the United States}

STEM education originated in the United States [2], which is a comprehensive application of interdisciplinary. The United States has been experimenting with STEM since the 19th century. Not only does the education department attach importance to STEM, but also the Congress, National Science Foundation, National Science Council, and the Ministry of Energy have established STEM education programs. In 1986 , the National Science Council published "Undergraduate Science, Mathematics, and Engineering Education" as a landmark report, which first proposed integrating science, mathematics, engineering, and technology education [3]. This report has far-reaching implications for the Bush administration and the Obama administration. In 2006, former US President George W. Bush announced the "America Competitiveness Plan," which led to the United States continuing to increase investment in STEM education. In early 2017, Trump signed two new STEM education bills. The content is to authorize NASA and NSF to encourage more women to enter the STEM field and work in the STEM field. In 2018, the US Department of Education allocated \$279 million for the STEM education program [4]. Throughout the development of "STEM education" in the United States, the early development is slow and the effect is not optimistic. Since the 21st century, STEM education in the United States has developed in an all-round way (see Table I).

TABLE I. DEVELOPMENT OF STEM IN THE U.S

\begin{tabular}{|c|c|c|}
\hline Year & Bill Name & Content \\
\hline 1862 & Land-Grant Act & Start trying to STEM \\
\hline 1986 & $\begin{array}{c}\text { Neal Panel's Report or } \\
\text { Undergraduate Science, } \\
\text { Mathematics and Engineering } \\
\text { Education }\end{array}$ & $\begin{array}{c}\text { The first time to put forward } \\
\text { the programmatic proposal } \\
\text { of “integration of science, } \\
\text { mathematics, engineering } \\
\text { and technology" }\end{array}$ \\
\hline 1996 & $\begin{array}{c}\text { Shaping the Future: Strategies } \\
\text { for Revitalizing Undergraduate } \\
\text { Education }\end{array}$ & $\begin{array}{c}\text { Identify STEM education as } \\
\text { part of K-12 education }\end{array}$ \\
\hline 2011 & $\begin{array}{c}\text { K-12 Framework for Science } \\
\text { Education: Practice, } \\
\text { Interdisciplinary Concepts and } \\
\text { Core Concepts }\end{array}$ & $\begin{array}{c}\text { Interdisciplinary curriculum } \\
\text { integration }\end{array}$ \\
\hline 2017 & $\begin{array}{c}\text { Presidential Memorandum } \\
\text { Trest }\end{array}$ & $\begin{array}{c}\text { Invest at least \$200 million } \\
\text { a year for STEM }\end{array}$ \\
\hline
\end{tabular}


The Project Lead the Way organization(PLTW) is the largest, non-profit STEM program provider in the United States. In 1997, PLTW first launched the STEM program for the "Engineering Road" to 12 secondary schools. As of April 2017, the PLTW organization has provided more than 10,500 STEM courses for more than 9,000 schools in 50 states and Washington, DC. More than 2.4 million students use the courses offered by PLTW and more than 35,000 teachers have participated in advanced training at PLTW [5].

STEM is an educational engineering project that is complex and practical. The US government regards it as an important starting point for improving national competitiveness. The PLTW organization has established a relatively complete STEM education standard system with the US federal and state governments, K-12 schools, universities, research institutes, and enterprises. It comprehensively covers STEM education objectives, educational evaluation criteria, teacher standards, curriculums standards and related equipment standards.

\section{B. In China}

Since 2012, research on STEM has been increasing in China. In 2015, the Ministry of Education first proposed to explore STEM education in "Guidelines on the comprehensive and in-depth promotion of education informationization during the 13th Five-Year Plan period (draft for comments)". In 2016, it clearly shows China's supportive attitude towards STEM in "the Education Informationization 13th Five-Year Plan" [6]. In June 2017, the China Academy of Educational Sciences officially established the STEM Education Research Center, which provided extremely important strategic support for the development of STEM in China. In May 2018, the Chinese Academy of Educational Sciences launched the "China STEM Education 2029 Innovation Action Plan", with the aim of cultivating more innovative talents to enhance China's competitiveness. In June 2018, the first China STEM Education Development Conference released the "China STEM Education White Paper" and "STEM Teacher Competency Rating Standards". The provincial and municipal colleges of science, teachers' training schools and universities jointly established 11 STEM Education Collaborative Innovation Centers, which created the National STEM Education Research Collaborative Innovation Network. In October 2019, the third China STEM Education Development Conference was based on the theme of "The Power of Integration - STEM and Subject Teaching". It demonstrates the close relationship between STEM education and social development. The support of the government or society is an important guarantee for the quality of STEM education (see Table II)
TABLE II. DEVELOPMENT OF STEM IN CHINA

\begin{tabular}{|c|c|}
\hline Year & Bill Name \\
\hline 2015 & $\begin{array}{c}\text { Guiding Opinions on the Comprehensive and In-depth } \\
\text { Promotion of Education Informationization during the 13th } \\
\text { Five-Year Plan Period (Draft for Comment) }\end{array}$ \\
\hline 2016 & Thirteenth Five-Year Plan for Education Informationization \\
\hline \multirow{3}{*}{2017} & China STEM Education 2029 Innovation Action Plan \\
\hline & China STEM Education White Paper \\
\hline & STEM Teacher Competency Rating Standard \\
\hline
\end{tabular}

In the past ten years, China's STEM has developed considerably and achieved nice results. In order to promote STEM education, the state and society actively respond to the call, which is effectively carried out. Three types of economic support methods are provided to promote STEM education in schools. There are paid to the students, paid to the teachers and paid to the school [7]. Beijing and Shenzhen provinces mainly choose the first method. Beijing government purchase service of STEM while Shenzhen City conducted the "four o'clock and half activities" pilot. Shanghai, Shandong, and Guangxi provinces mainly use the second method. Students in Shanghai are covered $100 \%$ by after-school services. Xi'an City and Zhejiang Province mainly adopt the method of granting separate subsidies to schools. Xi'an City set up a special budget for Innovation Education while Zhejiang Province approved the funding of innovative laboratory construction projects.

According to incomplete statistics, households receiving STEM education need to invest about 60,000 to $80,000 \mathrm{CNY}$ a year, which accounts for about $50 \%$ of household income in second- and third-tier cities. At the current level of education, STEM is only a choice for high-income people, and ordinary income families are difficult to accept STEM consistently. In the past year, the government has invested a lot, but it still cannot cultivate the universality of STEM. This is due to a series of problems caused by regional differences, uneven distribution of learning resources, and large differences in talent needs in different regions. Government should increase their investment in STEM and turn it into mass education. The family's expenditure on STEM is controlled within $10,000 \mathrm{CNY}$, which can better promote the development of STEM.

\section{CHALLENGES AND OPPORTUNITIES}

STEM in the United States has been carried out for more than 30 years. Its background is based on the national policy of education with the philosophy of pragmatism. In contrast, China has only focused on STEM in recent years, so the development of theory and practice does not have enough experience and cultural accumulation. There are mainly the following challenges:

- Firstly, a complete education evaluation system has not been established. Each industry has its own evaluation standards, and relevant departments need to improve China's STEM evaluation system as soon as possible. 
- Secondly, there is no coherent STEM system. STEM is involved in all stages, but the overall framework has not been formed.

- Thirdly, no teaching team dedicated to training STEM has been established. At present, there is a lack of a comprehensive teaching team that can integrate disciplines.

- Fourthly, no social linkage mechanism has been established. The perception of STEM education varies greatly among departments.

- Fifthly, there is no integration of STEM with Chinese characteristics. Chinese STEM learns more from American and European education methods, so it should establish its own STEM brand to play a better leading role.

\section{EVALUATION STRATEGY}

There are several ways to improve STEM with Chinese characteristics:

- Firstly, it is necessary to establish standards and evaluations for improving STEM in China. Standards can promote STEM in an orderly manner. Curriculum resources and teacher training should have corresponding standards to ensure quality and promote the sound development of STEM. This requires the National Development and Commission Reform, the Ministry of Education, and the Ministry of Finance to jointly formulate relevant STEM series policies. It may also require state agencies, enterprises, and institutions to formulate relevant education systems.

- Secondly, it is imperative to implement a talent development integration plan. STEM education should be lifelong education, which is from the child to adult learning stage. Otherwise there will be a lack of continuity. If there is no interest cultivation and skill storage in the lower grades, then there will be a lack of knowledge and skill base in the later stages. The goal is to serve the national talent development strategy.

- Thirdly, it is important to establish a platform for resource integration and teacher training. On the basis of the STEM teacher development platform, universities have established STEM teacher training. Teachers should be regularly trained to acquire new knowledge and keep up with the latest developments. Only in this way can we build a comprehensive faculty and cultivate innovative talents. In addition, it can cultivate the interdisciplinary comprehensive application ability of learners.

- Fourthly, we can build an integrated STEM of a social linkage mechanism in China. STEM is not something that a single institution can do, so it must work together through the whole society. Therefore, social institutions should work together to form a system of innovative collaboration. STEM is a systematic project, which requires long-term exploration. Under the Belt and Road Initiative, advanced experience and typical cases can be used to explore various effective models in order to be promoted in more regions of China.
- Fifthly, it is possible to establish an education brand with Chinese characteristics with historical heritage. It is necessary to promote the domestic STEM education process based on the spirit of artisans. We must combine the spirit of the times with the teaching philosophy and integrate socialist values into the whole process of national education. In addition, it is necessary to adhere to the excellent culture of Chinese characteristics and Chinese style in education. The craftsman spirit is an indispensable ideological weapon for the Chinese dream. It can complete the transition from "Made in China" to "Created in China" and better promote the whole-round development of people and overall social progress.

\section{CONCLUSION}

The Belt and Road cooperation has opened up the new horizon for China's development and opening-up. The perception of STEM is dynamic and constantly changing process during the Belt and Road. In the current context of China, STEM should be incorporated into the talent development strategy. It should be listed as a coherent lifelong learning movement and become a carrier for cultivating comprehensive qualities. STEM is in the critical period of economic transformation in China, and it urgently needs to incorporate creativity and innovation. Therefore, the development of STEM in China cannot blindly imitate the experience of other countries. So it is important to take the road of being more suitable for China's basic national conditions based on the spirit of artisans. And it is necessary to follow the principles of synergy, cooperation, openness, tolerance and innovation.

\section{ACKNOWLEDGMENT}

Authors are grateful to Talent Introduction Project of Shanghai Urban Construction Vocational College for the necessary research support.

\section{REFERENCES}

[1] Amy MacDonald,Carmen Huser,Shukla Sikder,Lena Danaia. Effective Early Childhood STEM Education: Findings from the Little Scientists Evaluation[J]. Early Childhood Education Journal,2020,48(7).

[2] Viacheslav Osadchyi,Nataliia Valko,Liudmyla Kuzmich,Nataliya Abdullaeva. Studies of impact of specialized STEM training on choice further education[J]. SHS Web of Conferences,2020,75.

[3] Yeping Li,Ke Wang,Yu Xiao,Jeffrey E. Froyd,Sandra B. Nite. Research and trends in STEM education: a systematic analysis of publicly funded projects[J]. International Journal of STEM Education,2020,7(3).

[4] Yeping Li,Ke Wang, Yu Xiao,Jeffrey E. Froyd. Research and trends in STEM education: a systematic review of journal publications[J]. International Journal of STEM Education,2020,7(1).

[5] Gary R. Pike,Kirsten Robbins. Expanding the Pipeline: the Effect of Participating in Project Lead the Way on Majoring in a STEM Discipline[J]. Journal for STEM Education Research,2019,2(1).

[6] Fengshen Sun, Yongliang Cui, Songhong Wang. Research on Mixed Learning Model in the Age of Education Informationization 2.0[J]. International Journal of Education and Management,2019,4(1).

[7] Anning Hu,Jacob Hibel. Where do STEM majors lose their advantage? Contextualizing horizontal stratification of higher education in urban China[J]. Research in Social Stratification and Mobility,2015,41. 